\title{
Propofol-based total intravenous anesthesia decreases the incidence of postoperative nausea and vomiting without affecting flap survival in free flap breast reconstruction
}

\author{
Li Yang ${ }^{1,2 \#}$, Ya-Jun $\mathrm{Xu}^{1,2 \#}$, Jian Shen ${ }^{1,2 \#}$, Fei-Fei Lou ${ }^{1,2}$, Jun Zhang ${ }^{1,2}$, Jiong $\mathrm{Wu}^{2,3}$ \\ ${ }^{1}$ Department of Anesthesiology, Fudan University Shanghai Cancer Center, Fudan University, Shanghai, China; ${ }^{2}$ Department of Oncology, Shanghai \\ Medical College, Fudan University, Shanghai, China; ${ }^{3}$ Department of Breast Surgery, Fudan University Shanghai Cancer Center, Fudan University, \\ Shanghai, China \\ Contributions: (I) Conception and design: L Yang, YJ Xu, FF Lou, J Wu; (II) Administrative support: J Shen, YJ Xu, J Zhang, FF Lou, J Wu; (III) \\ Provision of study materials or patients: FF Lou, J Wu; (IV) Collection and assembly of data: L Yang, J Shen, YJ Xu, FF Lou; (V) Data analysis and \\ interpretation: L Yang, YJ Xu, J Shen, FF Lou, J Wu; (VI) Manuscript writing: All authors; (VII) Final approval of manuscript: All authors. \\ "These authors contributed equally to this work. \\ Correspondence to: Prof. Jiong Wu. Department of Breast Surgery, Fudan University Shanghai Cancer Center, 270 Dong An Road, Xuhui, Shanghai \\ 200032, China. Email: wujiong1122@vip.sina.com; Prof. Jun Zhang. Department of Anesthesiology, Fudan University Shanghai Cancer Center, 270 \\ Dong An Road, Xuhui, Shanghai 200032, China. Email: snapzhang@allyun.com; Prof. Fei-Fei Lou. Department of Anesthesiology, Fudan University \\ Shanghai Cancer Center, 270 Dong An Road, Xuhui, Shanghai 200032, China. Email: loufeifei@sina.com.
}

\begin{abstract}
Background: Postoperative nausea and vomiting (PONV) may cause undesirable effects after microsurgical breast reconstruction. Although total intravenous anesthesia (TIVA) with propofol has been demonstrated to be effective in reducing PONV, it has not been assessed in autologous free flap breast reconstruction. The purpose of this study was to investigate the antiemetic prophylaxis effect and safety of TIVA in microvascular breast reconstruction.
\end{abstract}

Methods: Eighty-three patients undergoing microsurgical breast reconstruction with propofol (31 patients) or sevoflurane (52 patients) were retrospectively reviewed. The incidence of PONV was assessed at 2, 6, and 24 hours after surgery. Mean arterial blood pressure (MAP) was compared at $T_{1}$ (after flap elevation but before transfer), $\mathrm{T}_{2}$ (15 minutes after revascularization), and $\mathrm{T}_{3}$ (at the end of surgery).

Results: The incidence of nausea was significantly reduced in the TIVA group over 0 to 2 hours period $(\mathrm{P}=0.017)$, and over 2 to 6 hours period $(\mathrm{P}=0.033)$. The incidence of vomiting was significantly reduced in the TIVA group over 0 to 2 hours period $(\mathrm{P}=0.006)$, and over 2 to 6 hours period $(\mathrm{P}=0.005)$. MAP was higher in the TIVA group at $\mathrm{T}_{1}(\mathrm{P}=0.018), \mathrm{T}_{2}(\mathrm{P}=0.005)$, and $\mathrm{T}_{3}(\mathrm{P}=0.007)$. The incidence of flap failure was similar between the two groups $(\mathrm{P}=0.373)$.

Conclusions: Compared with sevoflurane maintaining anesthesia, propofol-based TIVA improves PONV with less fluctuation of MAP, and did not affect flap survival.

Keywords: Total intravenous anesthesia (TIVA); sevoflurane; deep inferior epigastric perforator flap (DIEP flap); postoperative nausea and vomiting (PONV)

Submitted Feb 14, 2020. Accepted for publication Aug 23, 2020.

doi: $10.21037 / \mathrm{gs}-20-225$

View this article at: http://dx.doi.org/10.21037/gs-20-225 


\section{Introduction}

Postoperative nausea and vomiting (PONV) is common following general anesthesia for deep inferior epigastric perforator (DIEP) flap breast reconstruction. PONV may cause undesirable consequences such as tension on suture lines, wound breakdown and hematoma formation $(1,2)$. Since patient-specific and surgery-related risk factors are rather constant, pharmacological interventions during anesthesia may be the breakthrough point for decreasing the incidence of PONV (2).

General anesthesia with inhalational anesthetics has been identified as one of the risk factors for PONV (3). Studies have shown that propofol-based total intravenous anesthesia (TIVA) may be effective in reducing the incidence of PONV in female patients undergoing breast surgery and other surgical procedures (4-6).

Free flaps, however, may be more vulnerable to hemodynamic instability and hypoperfusion during anesthesia. Preserving a good perfusion pressure and maintaining a hemodynamic stability are essential to achieve optimal circulation state and flap survival (7). Therefore, other effects of an anesthesia technique should be considered in addition to decreasing PONV.

The purpose of this study was to compare the incidence of PONV, intraoperative hemodynamic stability, and safety between propofol-based TIVA and sevoflurane anesthesia in DIEP flap breast reconstructive surgery. We present the following article in accordance with the STROBE reporting checklist (available at http://dx. doi. org/10. 21037/gs-20225).

\section{Methods}

\section{Patients}

From September 2014 to September 2019, 83 patients undergoing unilateral DIEP flap breast reconstruction under general anesthesia alone were included. Among them, 31 patients received propofol-based TIVA and 52 patients received sevoflurane anesthesia. All 83 patients were included for the analysis of flap and systemic complications and intraoperative hemodynamics. Two patients in the TIVA group and 5 patients in the sevoflurane group were excluded from the analysis of PONV because of the reoperation within 24 hours for flap compromise. All surgical procedures were performed by a single surgeon and all anesthetic procedures were administered by the same anesthesiology team. This study was conducted in accordance with the Declaration of Helsinki (as revised in 2013). This study was approved by Fudan University Shanghai Cancer Center Ethics Committee (No. IRB2007220-16) and informed consent was taken from all the patients.

\section{Anesthesia and analgesia}

General anesthesia was induced with sufentanil (0.1 to $0.2 \mathrm{mcg} / \mathrm{kg}$ ), propofol (1.5 to $2.5 \mathrm{mg} / \mathrm{kg}$ ), and rocuronium $(0.6 \mathrm{mg} / \mathrm{kg})$. After endotracheal intubation, propofol (4 to $12 \mathrm{mg} / \mathrm{kg} / \mathrm{h}$ ) or sevoflurane $(1.5 \%$ to $3.5 \%)$ was used for the maintenance of anesthesia. The depth of anesthesia was assessed by the Narcotrend (Monitor Technik, Bad Bramstedt, Germany) anesthesia awareness monitoring system and was maintained between levels D0 and D2 for all patients. Boluses of sufentanil were given intermittently as needed in both groups to maintain analgesia. Patient core temperature was closely monitored and was carefully maintained above $37{ }^{\circ} \mathrm{C}$ during surgery. Patients in both groups received the same PONV prophylaxis protocol: dexamethasone $4 \mathrm{mg}$ after induction combined with droperidol $0.625 \mathrm{mg}$ and granisetron $1 \mathrm{mg}$ at the end of surgery. For postoperative pain control, patients in both groups were given sufentanil using IV-patient controlled analgesia (PCA) (bolus dose of $1.5 \mu \mathrm{g}$ sufentanil with a continuous infusion rate of $1.5 \mu \mathrm{g} / \mathrm{h}$, and lockout interval of $6 \mathrm{~min})$.

\section{Data collection}

A retrospective chart review was performed from medical records to compile patient demographics (Table 1).

PONV risk factors (history of PONV and motion sickness, nonsmoking status), intraoperative and postoperative sufentanil administered were recorded. The incidence of PONV was assessed at 2, 6, and 24 hours after surgery. Patient satisfaction with PONV management was evaluated at 24 hours after surgery using a verbal rating scale, with a score of 0 representing highly dissatisfied and a score of 100 representing highly satisfied.

Before induction, a 20-gauge catheter was inserted into the radial artery after raising a skin wheal with $1 \%$ lidocaine. Mean arterial blood pressure (MAP) was documented before the induction of general anesthesia $\left(\mathrm{T}_{0}\right)$, at the completion of flap elevation before the transfer $\left(\mathrm{T}_{1}\right), 15$ minutes after vessel anastomoses $\left(\mathrm{T}_{2}\right)$, and at the end of surgery $\left(\mathrm{T}_{3}\right)$. Fluid variables included 
Table 1 Patient characteristics

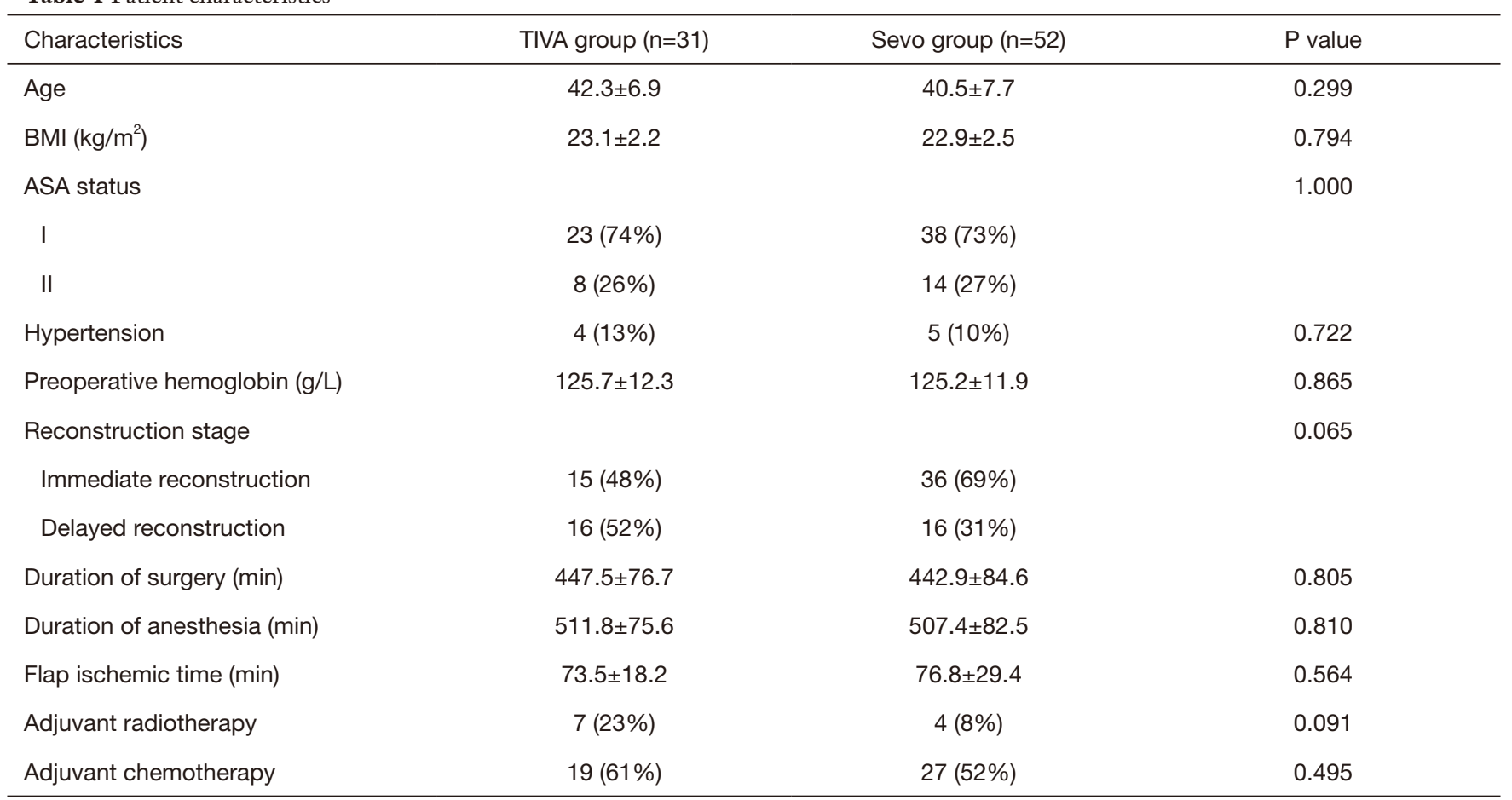

TIVA, total intravenous anesthesia; Sevo, sevoflurane; BMI, body mass index; ASA, American Society of Anesthesiologists.

total fluids, urine output, estimated blood loss and fluid balance.

Recovery profiles concerning extubation time, following verbal commands, orientation, intraoperative awareness, discharge from postanesthetic care unit (PACU), and duration of hospital stay were documented.

Intraoperative and postoperative flap and systemic complications were recorded. Flap complications included flap compromise (arterial thrombosis, venous thrombosis, and mechanical obstruction), partial or total flap loss, wound infection, delayed wound healing, and wound breakdown. Systemic complications such as deep vein thrombosis (DVT), pulmonary embolism, stroke, arrhythmia, myocardial infarction, pleural effusion, pneumonia, renal insufficiency was also collected.

Intraoperative propofol and sevoflurane consumption, and the cost of these anesthetic agents were analyzed.

\section{Statistical analysis}

Continuous variables were presented as median $\pm \mathrm{SD}$, and categorical variables were presented as numbers and proportions. Binary variables were analyzed using chisquare test or Fisher's exact test. Quantitative variables between the groups were analyzed using Student's $t$-test or Mann-Whitney U test. Repeated measured data were analyzed using repeated measure analysis of variance. Statistical significance was defined as $\mathrm{P}<0.05$, and all $\mathrm{P}$ values were two-sided. Data were analyzed using SPSS 16.0 (SPSS, Inc., Chicago, IL, USA).

\section{Results}

\section{Patient characteristics}

Patient age, BMI, ASA status, comorbidities, preoperative hemoglobin, reconstruction stage, duration of surgery and anesthesia, flap ischemic time, history of adjuvant radiotherapy and chemotherapy were comparable between the two groups (Table 1).

\section{PONV}

History of PONV and motion sickness, nonsmoking status, and intraoperative and postoperative sufentanil administered were similar between the two groups (Table 2).

The incidences of PONV at different postoperative time intervals are displayed in Table 2. Patients in the TIVA 
Table 2 PONV risk factors and incidence of PONV

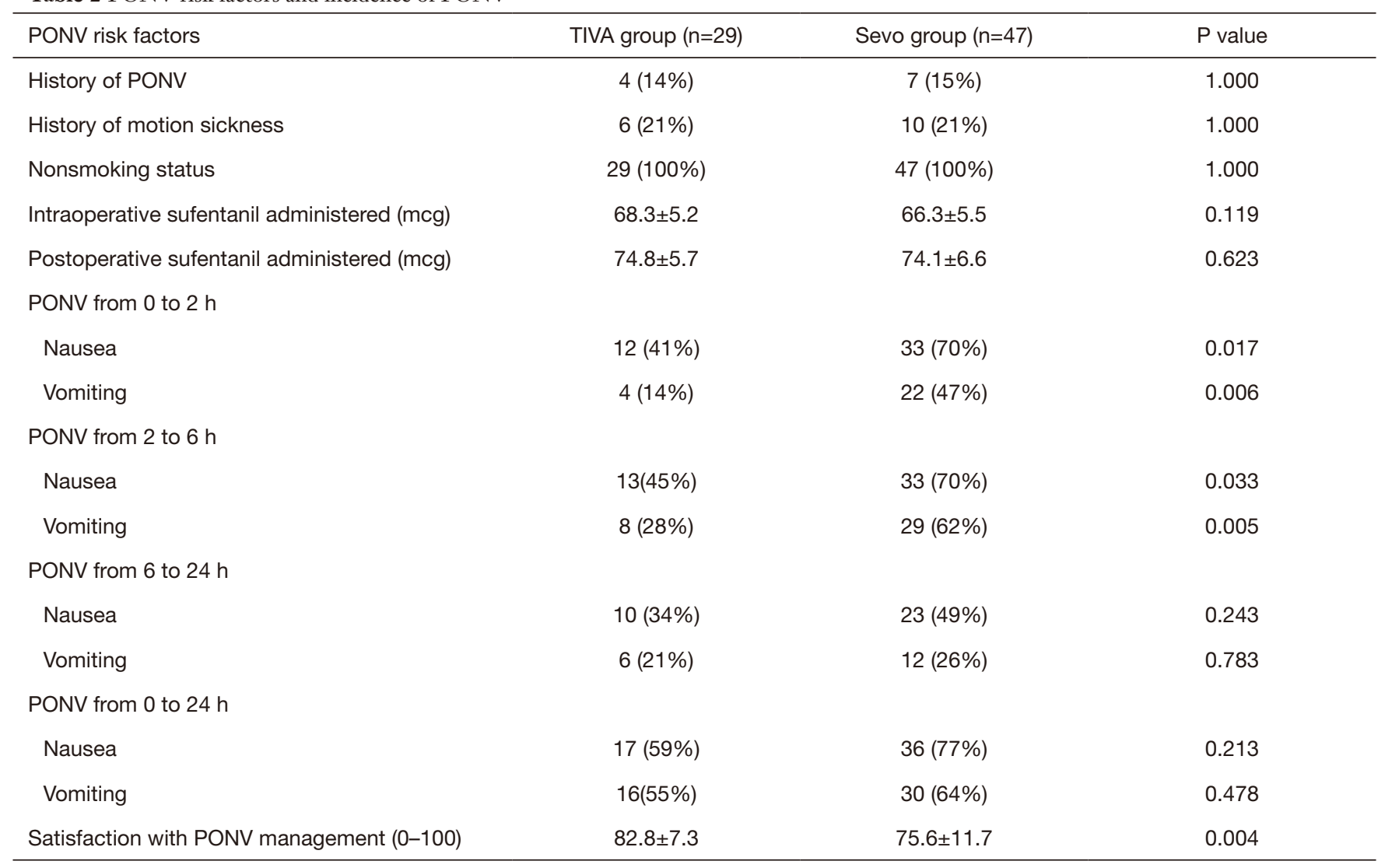

PONV, postoperative nausea and vomiting; TIVA, total intravenous anesthesia; Sevo, sevoflurane.

group experienced lower incidences of PONV over 0 to 2 hours, and 2 to 6 hours period. There was no difference in the incidence of PONV over 6 to 24 hours, and 0 to 24 hours period between the two groups.

Patient satisfaction with PONV management was higher in the TIVA group than that in the sevoflurane group (Table 2).

\section{Intraoperative bemodynamics and fluid balance}

MAP at different perioperative time points are shown in Table 3. Compared to the baseline at $\mathrm{T}_{0}$ (before induction of general anesthesia), MAPs decreased significantly at $T_{1}$, $\mathrm{T}_{2}$ and $\mathrm{T}_{3}$ in both groups (repeated measure analysis of variance, $\mathrm{P}<0.05)$. However, higher MAP was observed at $\mathrm{T}_{1}, \mathrm{~T}_{2}$ and $\mathrm{T}_{3}$ in the TIVA group compared with that in the sevoflurane group.

There were no differences in total fluid administration, urine output, estimated blood loss, or fluid balance between the two groups (Table 3).

\section{Postoperative recovery}

Extubation time, following verbal commands, orientation, intraoperative awareness, discharge from PACU, and length of hospital stay did not differ between the two groups (Table 4).

\section{Flap and systemic complications}

Two patients in the TIVA group and 5 patients in the sevoflurane group developed flap compromise (6.5\% versus $9.6 \% ; \mathrm{P}=0.707$ ) (Table 5). These patients underwent a second operation for flap salvage. One flap compromise in the TIVA group was due to venous thrombosis and the other, mechanical compression. The latter was salvaged and the former, lost. All 5 flap compromises in the sevoflurane group were due to mechanical compression of the pedicle vein and were successfully salvaged (Table 5). There were no arterial thromboses in this series. There were no differences of flap compromise $(6.5 \%$ versus $9.6 \% ; \mathrm{P}=0.707)$ and flap 
Table 3 Intraoperative hemodynamics and fluid balance

\begin{tabular}{lccc}
\hline Variable & TIVA group $(\mathrm{n}=31)$ & Sevo group $(\mathrm{n}=52)$ & P value \\
\hline MAP at $\mathrm{T}_{0}(\mathrm{mmHg})$ & $90.1 \pm 11.2$ & $90.3 \pm 8.9$ & 0.925 \\
MAP at $\mathrm{T}_{1}(\mathrm{mmHg})$ & $86.1 \pm 8.4$ & $81.4 \pm 7.3$ & 0.018 \\
MAP at $\mathrm{T}_{2}(\mathrm{mmHg})$ & $86.0 \pm 7.3$ & $81.2 \pm 7.3$ & 0.005 \\
MAP at $\mathrm{T}_{3}(\mathrm{mmHg})$ & $88.5 \pm 7.6$ & $84.1 \pm 6.6$ & 0.007 \\
Total fluids $(\mathrm{mL})$ & $2,696.8 \pm 518.0$ & $2,717.3 \pm 595.0$ & 0.874 \\
Urine output $(\mathrm{mL})$ & $1,153.2 \pm 383.4$ & $1,061.5 \pm 391.3$ & 0.301 \\
Estimated blood loss $(\mathrm{mL})$ & $100.0 \pm 56.3$ & $105.8 \pm 56.6$ & 0.654 \\
Fluid balance $(\mathrm{mL})$ & $1,453.8 \pm 535.6$ & $1,511.3 \pm 501.8$ & 0.630 \\
\hline
\end{tabular}

TIVA, total intravenous anesthesia; Sevo, sevoflurane; MAP, mean arterial blood pressure; $T_{0}$, before induction of general anesthesia; $T_{1}$, after flap dissection and elevation before flap transfer; $T_{2}, 15$ minutes after vessel anastomoses; $T_{3}$, at the end of surgery.

Table 4 Postoperative recovery

\begin{tabular}{lccc}
\hline Variable & TIVA group $(\mathrm{n}=31)$ & Sevo group $(\mathrm{n}=52)$ & $\mathrm{P}$ value \\
\hline Extubation time $(\mathrm{min})$ & $6.7 \pm 0.8$ & $6.5 \pm 0.8$ & 0.340 \\
Following verbal commands $(\mathrm{min})$ & $8.0 \pm 0.9$ & $8.2 \pm 0.8$ & 0.233 \\
Orientation (min) & $8.8 \pm 1.1$ & $9.1 \pm 1.0$ & 0.233 \\
Intraoperative awareness & $0(0.0 \%)$ & $0(0.0 \%)$ & 1.000 \\
Discharge from PACU (min) & $38.7 \pm 7.6$ & $39.4 \pm 7.3$ & 0.672 \\
Duration of hospital stay (d) & $6.9 \pm 1.8$ & $6.9 \pm 2.2$ & 0.883 \\
\hline
\end{tabular}

TIVA, total intravenous anesthesia; Sevo, sevoflurane; PACU, postanesthetic care unit.

failure (3.2\% versus $0.0 \% ; \mathrm{P}=0.373$ ) between the two groups (Table 5). One patient in the sevoflurane group developed pleural effusion. The incidences of systemic complications were similar $(0.0 \%$ versus $1.9 \% ; \mathrm{P}=1.000)$ between the two groups (Table 5).

\section{Cost analyses}

The TIVA group showed a significantly higher cost for the maintenance of anesthesia than the sevoflurane group $(1,642.8 \pm 317.7$ versus $910.0 \pm 175.5 \mathrm{CNY}, \mathrm{P}<0.001)$ (Table 6).

\section{Discussion}

Studies have shown that PONV is associated with high levels of patient dissatisfaction and discomfort, and avoidance of PONV may be even in greater demand than avoidance of postoperative pain $(2,8)$. The reported overall incidence of PONV is approximately $30 \%$ after elective operations and can be as high as $70 \%$ in high-risk patients $(2,9)$. DIEP flap breast reconstruction involves several identified PONV risk factors. These risk factors include female gender, long duration of surgery, certain type of surgery (breast, plastic surgery), and perioperative opioid administration. According to a study carried out by Manahan et al., 76\% of DIEP patients experienced PONV, and about two third of patients experienced emesis (2). The results from our study are in agreement with their findings. In the sevoflurane group, the incidence of postoperative nausea and postoperative vomiting during the first 24 hours was $77 \%$ and $65 \%$, respectively.

Early PONV occurs within 6 hours after surgery, often in the PACU (2). Late PONV occurs between 6 to 24 hours postoperatively and is usually associated with opioid use. PONV occurring after 24 hours is termed as delayed PONV, which can be related to opioid use and/or early mobilization after surgery (10).

The exact mechanisms of PONV are still unclear and 
Table 5 Flap and systemic complications

\begin{tabular}{lccc}
\hline Variable & TIVA group $(\mathrm{n}=31)$ & Sevo group $(\mathrm{n}=52)$ & $\mathrm{P}$ value \\
\hline Flap compromise & $2(6.5 \%)$ & $5(9.6 \%)$ & 0.707 \\
Flap arterial thrombosis & $0(0.0 \%)$ & $0(0.0 \%)$ & 0.000 \\
Flap venous thrombosis & $1(3.2 \%)$ & $0(0.0 \%)$ & 0.373 \\
Mechanical obstruction & $1(3.2 \%)$ & $5(9.6 \%)$ & 0.403 \\
Partial flap loss & $0(0.0 \%)$ & $0(0.0 \%)$ & 1.000 \\
Total flap loss & $1(3.2 \%)$ & $0(0.0 \%)$ & 1.373 \\
Wound infection & $0(0.0 \%)$ & $1(1.9 \%)$ & 1.000 \\
Delayed wound healing & $0(0.0 \%)$ & $1.9 \%)$ & 1.000 \\
Wound breakdown & $0(0.0 \%)$ & $0(0.0 \%)$ & 1.000 \\
Systemic complications & $0(0.0 \%)$ & $1(1.9 \%)$ & 1.000 \\
\hline
\end{tabular}

Systemic complications included deep vein thrombosis, pulmonary embolism, stroke, arrhythmia, myocardial infarction, pleural effusion, pneumonia, renal insufficiency, and others. TIVA, total intravenous anesthesia; Sevo, sevoflurane.

Table 6 Cost analyses

\begin{tabular}{lcc}
\hline Variable & TIVA group $(\mathrm{n}=31)$ & Sevo group $(\mathrm{n}=52)$ \\
\hline Intraoperative propofol $(\mathrm{mg})$ & $3,854.4 \pm 745.3$ & $117.9 \pm 13.9$ \\
Intraoperative sevoflurane $(\mathrm{mL})$ & $0.0 \pm 0.0$ & $89.5 \pm 18.2$ \\
Cost of propofol $(\mathrm{CNY})[\mathrm{propofol} 1 \%(20 \mathrm{~mL})=85.24 \mathrm{CNY}]$ & $1,642.8 \pm 317.7$ & $50.2 \pm 5.9$ \\
Cost of sevoflurane $(\mathrm{CNY})$ [sevoflurane $(250 \mathrm{~mL})=2,402.41$ & $0.0 \pm 0.0$ & $859.7 \pm 174.4$ \\
CNY] & $1,642.8 \pm 317.7$ & $<0.001$ \\
Total cost $(\mathrm{CNY})$ & $<0.001$ & $<0.001$ \\
\hline
\end{tabular}

TIVA, total intravenous anesthesia; Sevo, sevoflurane; CNY, Chinese Yuan.

may be complex. In general, the occurrence of PONV can be ascribed to patient-specific risk factors (female sex, history of PONV or motion sickness), anesthetic risk factors (volatile anesthetics, opioid), and surgical risk factors (certain types of surgery and operative sites, increased duration of surgery) (11-14). In a randomized controlled trial of 1180 PONV high-risk patients, volatile anesthetics were identified as the main cause of vomiting that occurred within 2 hours after surgery (15). Sneyd et al. in another study demonstrated that the use of propofol throughout the surgical procedure effectively decreased the incidence of PONV (16). Our current study seems to support these findings.

Propofol is commonly used in induction of general anesthesia. Such use does not seem to protect patients from PONV when maintenance of anesthesia is provided with inhalation $(17,18)$. Patients in the sevoflurane group in our study also received propofol during induction. Our results and others suggest that a therapeutic plasma level of propofol may be necessary to be effective in reducing PONV (4). Thus, maintenance of anesthesia with propofol is required to achieve this effect. Possible mechanisms of the protective effect of propofol against PONV may include the inhibition of 5-hydroxy-tryptamin-3 $\left(5-\mathrm{HT}_{3}\right)$ receptor of serotonergic system and the blockade of vagal nuclei and chemoreceptor trigger zone (CTZ) although the exact mechanisms remain unclear $(6,19)$.

It is well known that $\mu$ opioid receptor agonists, such as sufentanil, can elicit PONV because of direct stimulation of the CTZ (20). Theoretically, intraoperative use of opioids could diminish the protective effects of propofol. Sufentanil is commonly used during anesthesia to provide supplement analgesia. Its use is gauged by changes in vital signs such as blood pressure, heart rate, or Narcotrend values indicating 
surgical stress or lightening of analgesia and is discontinued at least 30 minutes before the end of surgery to avoid adverse respiratory depression (20,21). Because of its long half-life (162 minutes), the intraoperative and postoperative use of sufentanil may have some effect on PONV. Therefore, control of this variable is important. In the present study, the total dose of sufentanil was not different between the propofol group and sevoflurane group.

Maintaining a hemodynamic stability during a long surgery is a challenge, especially in microsurgical free flap transfer (22). Prolonged and severe hypotension can be detrimental to flap perfusion $(22,23)$. Both propofol and sevoflurane can cause hypotension. Propofol directly suppresses vascular reactivity resulting in the decrease of MAP. On the other hand, sevoflurane has been shown to inhibit myocardial contractility and possess the vasodilatory effect. Whether one agent has more profound hemodynamic disturbance than the other is inconclusive from previous studies. Lauta $e t$ al. showed that patients undergoing neurosurgical procedures experienced more frequent episodes of hypotension in the sevoflurane group than in the propofol group (24). Similarly, Claroni et al. reported that patients undergoing free flap breast reconstruction maintained a higher MAP in the propofol group than in the sevoflurane group, although the differences were not statistically significant (25). Gravel et al., however, demonstrated that fewer interventions were required intraoperatively in the management of systemic blood pressure in the sevoflurane group than in the propofol group in coronary artery bypass graft (CABG) surgery (26). Watson et al. found that the stability of cardiovascular system was comparable between the propofol group and the sevoflurane group (27).

To compare the hemodynamic effects of these two agents during free flap breast reconstruction, MAPs were carefully monitored throughout the case and evaluated at different key time points. At $\mathrm{T}_{1}$, all the perforators and the main vascular pedicle of the DIEP flap had been dissected out while the pedicle was still attached. The flap was perfused through its native deep inferior epigastric vessels. At $T_{2}$, the flap vascular pedicle was severed, the flap was moved to the chest recipient site, and revascularization was completed by anastomosing the flap pedicle to the internal mammary vessels. MAP was taken 15 minutes after revascularization to allow the flap to reach a steady state perfusion. At $T_{3}$, the surgical procedures were completed and patients were ready for waking up. MAPs at these time points were compared to their baseline before the induction of anesthesia $\left(\mathrm{T}_{0}\right)$.
Intraoperative blood pressure can also be affected by the depth of anesthesia. None of the previous studies mentioned this variable. The lack of precise control of this variable might also have contributed to the inconsistent findings in previously published literature. In our practice, the depth of anesthesia is carefully assessed with the Narcotrend anesthesia awareness monitoring system and was maintained between levels D0 and D2. Such a consistent and precise control of anesthesia depth by a single anesthesiology team is likely to make the two groups more comparable.

Our study demonstrated that MAP was significantly lower in the sevoflurane group at all three intraoperative time points compared to that in the TIVA group. Therefore, using propofol for the maintenance of anesthesia has a secondary benefit of minimizing hemodynamic instability.

One of the concerns regarding propofol-based TIVA in prolonged surgery is that propofol might delay extubation, thus causing unnecessary prolonged stay in PACU (4). We find that the use of anesthesia awareness monitoring system is very helpful in controlling the depth of anesthesia and preparing for wake-up at the end of surgery. We have not experienced delays in extubation because of propofol use. In fact, the extubation time was nearly identical in the TIVA and sevoflurane groups. Similar findings have also been reported in other breast and colorectal surgeries $(4,28)$.

In intraoperative management of free flap, the safety of flap has always been one of the prime considerations for anesthetists. Sevoflurane has been proved to provide better endothelial protection from ischemia-reperfusion injury than propofol in in-vivo situation (29). However, the influence on the safety of free flap between propofol and sevoflurane has not been widely studied. Our study showed that propofol-based TIVA didn't adversely affect free flap survival, thus indicating the safety of TIVA in microvascular breast reconstruction.

Although propofol showed the benefits in PONV prophylaxis and hemodynamic control, however, our cost analysis showed that using propofol for the maintenance of anesthesia was less cost-effective than using sevoflurane.

Limitation of this study is the relatively small sample of 83 cases. Further study could be continued to recruit more cases in both groups to strengthen the power of the analysis.

In summary, the findings of the present study suggest that, compared to using sevoflurane in anesthesia maintenance, propofol-based TIVA reduces the incidence of PONV in DIEP flap breast reconstruction and improves intraoperative hemodynamics without delaying extubation or risking free flap survival. 


\section{Acknowledgments}

We would like to thank Drs. Zhen Hu, Xiaoyan Huang, Ayong Cao, Jiajian Chen, Benlong Yang, and Yingying Zhang, for their assistance in this study, and Peirong Yu, MD, Professor in the Department of Plastic Surgery, MD Anderson Cancer Center, Houston, TX, for his assistance in manuscript editing.

Funding: None.

\section{Footnote}

Reporting Checklist: The authors have completed the STROBE reporting checklist. Available at http://dx. doi. org/10. 21037/gs-20-225

Data Sharing Statement: Available at http://dx. doi. org/10. 21037/gs-20-225

Conflicts of Interest: All authors have completed the ICMJE uniform disclosure form (available at http://dx. doi. org/10.21037/gs-20-225). The authors have no conflicts of interest to declare.

Ethical Statement: The authors are accountable for all aspects of the work in ensuring that questions related to the accuracy or integrity of any part of the work are appropriately investigated and resolved. This study was conducted in accordance with the Declaration of Helsinki (as revised in 2013). This study was approved by Fudan University Shanghai Cancer Center Ethics Committee (No. IRB2007220-16) and informed consent was taken from all the patients.

Open Access Statement: This is an Open Access article distributed in accordance with the Creative Commons Attribution-NonCommercial-NoDerivs 4.0 International License (CC BY-NC-ND 4.0), which permits the noncommercial replication and distribution of the article with the strict proviso that no changes or edits are made and the original work is properly cited (including links to both the formal publication through the relevant DOI and the license). See: https://creativecommons.org/licenses/by-nc-nd/4.0/.

\section{References}

1. Temple-Oberle C, Shea-Budgell MA, Tan M, et al. Consensus Review of Optimal Perioperative Care in
Breast Reconstruction: Enhanced Recovery after Surgery (ERAS) Society Recommendations. Plast Reconstr Surg 2017;139:1056e-71e.

2. Manahan MA, Basdag B, Kalmar CL, et al. Risk of severe and refractory postoperative nausea and vomiting in patients undergoing diep flap breast reconstruction. Microsurgery 2014;34:112-21.

3. Matsuura H, Inoue S, Kawaguchi M. The risk of postoperative nausea and vomiting between surgical patients received propofol and sevoflurane anesthesia: A matched study. Acta Anaesthesiol Taiwan 2016;54:114-20.

4. Chen HP, Hsu YH, Hua KC, et al. Comparison of sevoflurane versus propofol under auditory evoked potential monitoring in female patients undergoing breast surgery. Biomed J 2013;36:125-31.

5. Yoo YC, Bai SJ, Lee KY, et al. Total intravenous anesthesia with propofol reduces postoperative nausea and vomiting in patients undergoing robot-assisted laparoscopic radical prostatectomy: a prospective randomized trial. Yonsei Med J 2012;53:1197-202.

6. Vasileiou I, Xanthos T, Koudouna E, et al. Propofol: a review of its non-anaesthetic effects. Eur J Pharmacol 2009;605:1-8.

7. Hagau N, Longrois D. Anesthesia for free vascularized tissue transfer. Microsurgery 2009;29:161-7.

8. Macario A, Weinger M, Carney S, et al. Which clinical anesthesia outcomes are important to avoid? The perspective of patients. Anesth Analg 1999;89:652-8.

9. Lou F, Sun Z, Huang N, et al. Epidural Combined with General Anesthesia versus General Anesthesia Alone in Patients Undergoing Free Flap Breast Reconstruction. Plast Reconstr Surg 2016;137:502e-9e.

10. American Society of PeriAnesthesia Nurses PONV/PDNV Strategic Work Team. ASPAN'S evidence-based clinical practice guideline for the prevention and/or management of PONV/PDNV. J Perianesth Nurs 2006;21:230-50.

11. White PF. Prevention of postoperative nausea and vomiting--a multimodal solution to a persistent problem. N Engl J Med 2004;350:2511-2.

12. Watcha MF, White PF. Postoperative nausea and vomiting. Its etiology, treatment, and prevention. Anesthesiology 1992;77:162-84.

13. Leslie K, Myles PS, Chan MT, et al. Risk factors for severe postoperative nausea and vomiting in a randomized trial of nitrous oxide-based vs nitrous oxide-free anaesthesia. $\mathrm{Br} \mathrm{J}$ Anaesth 2008;101:498-505.

14. Habib AS, Gan TJ. Evidence-based management of postoperative nausea and vomiting: a review. Can J 
Anaesth 2004;51:326-41.

15. Apfel CC, Kranke P, Katz MH, et al. Volatile anaesthetics may be the main cause of early but not delayed postoperative vomiting: a randomized controlled trial of factorial design. Br J Anaesth 2002;88:659-68.

16. Sneyd JR, Carr A, Byrom WD, et al. A meta-analysis of nausea and vomiting following maintenance of anaesthesia with propofol or inhalational agents. Eur J Anaesthesiol 1998; 15:433-45.

17. de Grood PM, Harbers JB, van Egmond J, et al. Anaesthesia for laparoscopy. A comparison of five techniques including propofol, etomidate, thiopentone and isoflurane. Anaesthesia 1987;42:815-23.

18. Chittleborough MC, Osborne GA, Rudkin GE, et al. Double-blind comparison of patient recovery after induction with propofol or thiopentone for day-case relaxant general anaesthesia. Anaesth Intensive Care 1992;20:169-73.

19. Appadu BL, Strange PG, Lambert DG. Does propofol interact with D2 dopamine receptors? Anesth Analg 1994;79:1191-2.

20. Hurford WE, Bailin MT, Davison JK. 6th ed. Clinical anesthesia procedures of the Massachusetts General Hospital; 2002:162-5.

21. Stoelting RK. Miller RD. 4th ed. Intravenous Anesthetics, in Basics of Anesthesia; 2000:58-69.

22. Motakef S, Mountziaris PM, Ismail IK, et al. Emerging paradigms in perioperative management for microsurgical free tissue transfer: review of the literature and evidencebased guidelines. Plast Reconstr Surg 2015;135:290-9.

Cite this article as: Yang L, Xu YJ, Shen J, Lou FF, Zhang J, Wu J. Propofol-based total intravenous anesthesia decreases the incidence of postoperative nausea and vomiting without affecting flap survival in free flap breast reconstruction. Gland Surg 2020;9(5):1406-1414. doi: 10.21037/gs-20-225
23. Chen C, Nguyen MD, Bar-Meir E, et al. Effects of vasopressor administration on the outcomes of microsurgical breast reconstruction. Ann Plast Surg 2010;65:28-31.

24. Lauta E, Abbinante C, Del GA, et al. Emergence times are similar with sevoflurane and total intravenous anesthesia: results of a multicenter RCT of patients scheduled for elective supratentorial craniotomy. J Neurosurg Anesthesiol 2010;22:110-8.

25. Claroni C, Torregiani G, Covotta M, et al. Protective effect of sevoflurane preconditioning on ischemiareperfusion injury in patients undergoing reconstructive plastic surgery with microsurgical flap, a randomized controlled trial. BMC Anesthesiol 2016;16:66.

26. Gravel NR, Searle NR, Taillefer J, et al. Comparison of the hemodynamic effects of sevoflurane anesthesia induction and maintenance vs TIVA in CABG surgery. Can J Anaesth 1999;46:240-6.

27. Watson KR, Shah MV. Clinical comparison of 'single agent' anaesthesia with sevoflurane versus target controlled infusion of propofol. Br J Anaesth 2000;85:541-6.

28. Chan WH, Lee MS, Lin C, et al. Comparison of Anesthesia-Controlled Operating Room Time between Propofol-Based Total Intravenous Anesthesia and Desflurane Anesthesia in Open Colorectal Surgery: A Retrospective Study. PLoS One 2016;11:e0165407.

29. Annecke T, Rehm M, Bruegger D, et al. Ischemiareperfusion-induced unmeasured anion generation and glycocalyx shedding: sevoflurane versus propofol anesthesia. J Invest Surg 2012;25:162-8. 